\title{
High-Tech Architecture Perspectives of Sports Hub in Singapore
}

\author{
Muhammad Agung Reynaldi \\ Architecture Department \\ Faculty of Civil Engineering and \\ Planning, University of Trisakti \\ Jakarta, Indonesia \\ muhammadagungreynaldi@gmail.com
}

\author{
Etty Retnowati Kridarso \\ Architecture Department \\ Faculty of Civil Engineering and \\ Planning, University of Trisakti \\ Jakarta, Indonesia \\ etty.k@trisakti.ac.id
}

\author{
Julindiani Iskandar \\ Architecture Department \\ Faculty of Civil Engineering and \\ Planning, University of Trisakti \\ Jakarta, Indonesia \\ lhamanov@gmail.com
}

\begin{abstract}
- in the 21st century, the need for effectiveness and flexibility in any activity is a necessity that must be fulfilled so that people can compete well. One of the examples is sports. The need, especially in sports, is marked by the growth of interest in sports in developed or developing countries. Besides, to fulfill the need for effectiveness and flexibility, architecture continues to innovate by creating a space that can accommodate the needs of people's lifestyles in the 21st century. Sports Hub is a sports destination consisting of the sports center and support facilities such as commercial centers, retails, and communal spaces. Sports Hub has a structured arrangement of interconnected spaces so that users can easily access various kinds of facilities in the building. Singapore, which is categorized as a developed country in Southeast Asia, has an Olympic-scale sports hub that can accommodate various types of events, such as Olympic games, music concerts, national events, etc. the Singapore Sports Hub located in Kallang, which was built in 2014. Based on observation, Singapore Sports Hub has applied High-tech architecture principles, such as by exposing the interior and structure (inside out), the use of transparent materials on the roof cover, and has inner space and outer space that can be functioned for certain occasions (flexible space). For these facts, this study aims to find out the maximum and effective use of the High-tech architecture principles in Singapore Sports Hub. To study and explore the building, this study used a qualitative method that is sourced from secondary data such as printed and electronic literature. The object of observation is reviewed by high-tech architecture principles so that the tentative conclusions can be obtained through aligning both data. Conclusions are drawn based on the number of aspects that fulfilled the Hightech architecture criteria. The objects are assessed by using the principles of High-tech architecture, such as; block plan (building mass), site plan (outdoor space), floor plan (indoor space), structure, material, and façade. Based on data and analysis, it has been acquired that the application of the Hightech architecture principles of Singapore Sports Hub in Kallang, Singapore, has applied six out of seven principles of High-tech architecture optimally, specifically: 1 . Inside out, 2. Celebration of process, 3. Transparent, coating and movement, 4. Lightweight and tensile structure, 5. Optimistic in scientific culture, 6. Flexible space.
\end{abstract}

Keywords: innovation, Sports hub, Singapore, High-tech

\section{INTRODUCTION}

Sport is a form of physical activity that can fulfill the essential needs of humans both physically and spiritually. In fulfilling the need for sports, infrastructure is needed as a place of activity.

Sports Hub, a sports destination, consists of a collection of sports centers that can accommodate mass sports activities.

One of the countries in Southeast Asia, Singapore that has been recognized as a developed country, has had an Olympic / National scale sports hub which was built in 2014 in Kallang, Singapore.

Singapore Sports Hub, which occupies an area of 35 hectares, has the concept of an integrated sports center with supporting facilities (entertainment and lifestyle hub). Based on observations, the Singapore Sports Hub has applied particular High-tech principles that can be observed directly from the shape of the building's mass and façade. The shape of a building resembles a dome that has an enclosure that exposed the interior. The space organization form that applied to the building is a centralized organization, where the support facilities are oriented as the secondary mass to the main building which facilitates user accessibilities. The use of materials that applied to build façades used the latest materials that represent future materials.

The existence of this building is expected to be a guideline in designing a Sports Hub that applies High-tech architecture.

Based on the data above, the problem can be formulated as follows:

- What is the application of High-tech architecture principles on Singapore Sports Hub?

The research objectives are:

- Know how big the application of High-tech Architecture principles on Singapore Sports Hub.

\section{LITERATURE REVIEW}

\section{A. Understanding of Sports Center}

Related, in the book of 'Design for Sport', sports center is an extension of a certain scale that can be associated with a sports hall that provides other facilities that are useful to the community [9]. The sports center can be a gymnasium that accommodates sports activities both exercise, recreation, and competitive activities. 
5. Special Disability Scale, sports facilities that deal with certain types of sports that are commercial or that are intended specifically for persons with disabilities, are usually formed by private parties. Example: GOR Lodya, Bandung.

1. National Scale, these sports facilities accommodate or service activities including major competitions, training, and teaching with international standards such as PON. Example: Bung Karno Stadium (national stadium), Central Jakarta.

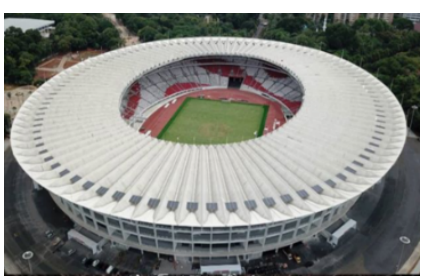

Fig. 1. Gelora Bung Karno Stadium

Source: Processed from Google Maps Pro 2019

2. Regional Scale, sports facilities that serve one or several regions with a population of 200,000 to 350,000 residents. Example: Dimiyati Sports Arena, Tangerang.

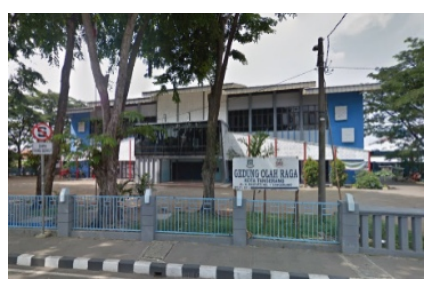

Fig. 2. Dimiyati Sports Center of Tangerang City Source: Field Observation, 2019

3. District Scale, sports facilities that serve residential neighborhoods with a population of 2,000 - 10,000 people, and are provided in a housing complex as a complementary facility. Example: Multisports Arena of Cendrawasih, West Jakarta.

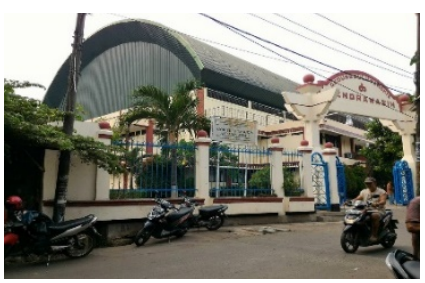

Fig. 3. Cendrawasih Sports Center of Cengakareng District Source: Field Observation, 2019

4. Schools Scale, this sports facility serves sports in a school, usually in the form of a hall, versatile space and it is used for standard exercise only. Example: Multipurpose hall of SMK Telkom, West Jakarta.
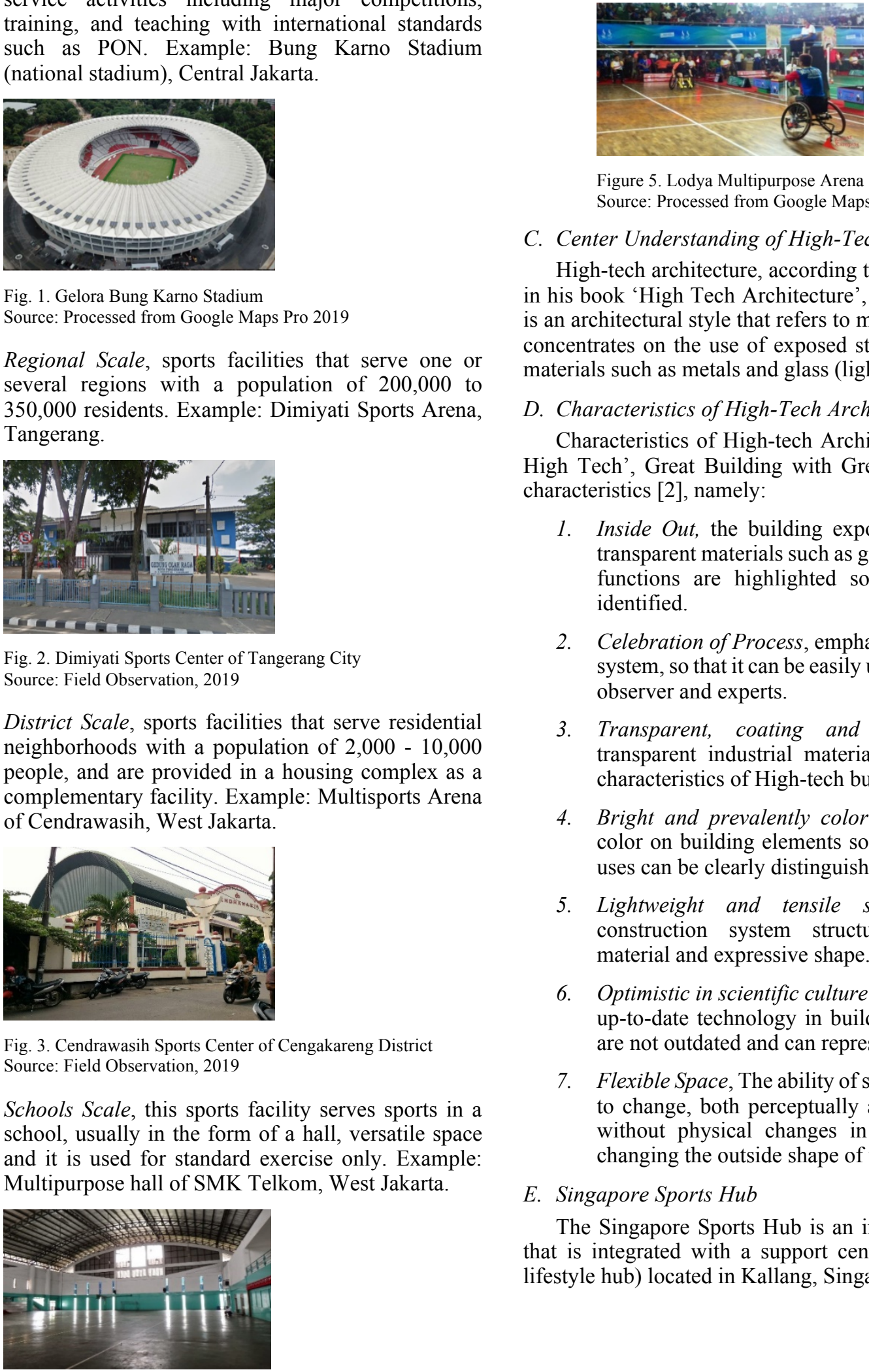

Figure 5. Lodya Multipurpose Arena

Source: Processed from Google Maps Pro 2019

\section{Center Understanding of High-Tech Architecture}

High-tech architecture, according to Colin Davies (1998), in his book 'High Tech Architecture', High-tech architecture is an architectural style that refers to modern architecture that concentrates on the use of exposed structures and industrial materials such as metals and glass (lightweight materials).

\section{Characteristics of High-Tech Architecture}

Characteristics of High-tech Architecture, 'The Battle of High Tech', Great Building with Great Faults, has 7 main characteristics [2], namely:

1. Inside Out, the building exposes the interior using transparent materials such as glass. Service and utility functions are highlighted so that they are easily identified.

2. Celebration of Process, emphasis on the construction system, so that it can be easily understood by common observer and experts.

3. Transparent, coating and movement, featured transparent industrial materials that can shape the characteristics of High-tech buildings.

4. Bright and prevalently color, bright and prevalent color on building elements so that the functions and uses can be clearly distinguished by observers

5. Lightweight and tensile structure, use of a construction system structure with lightweight material and expressive shape.

6. Optimistic in scientific culture, apply the latest / most up-to-date technology in buildings so that buildings are not outdated and can represent the future.

7. Flexible Space, The ability of space to be able to adapt to change, both perceptually and physically with or without physical changes in the building without changing the outside shape of the building.

\section{E. Singapore Sports Hub}

The Singapore Sports Hub is an integrated sports center that is integrated with a support center (entertainment and lifestyle hub) located in Kallang, Singapore built-in 2014 [5].

Fig. 4. Multipurpose hall of SMK Telkom

Source: Field Observation, 2019 

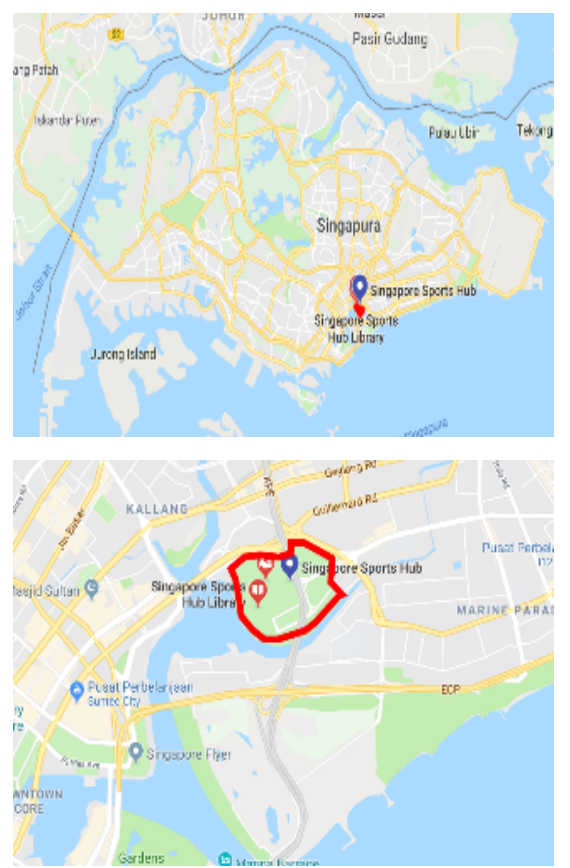

Figure 6. Singapore Sports Hub location

Source: Processed from Google Maps Pro 2019

The Singapore Sports Hub is located on a 35 hectares area, consisting of:

1. National Stadium with a capacity of 55,000 visitors (retractable roof and movable grandstand).

2. Aquatic Stadium with a capacity of 6,000 visitors (FINA Standard).

3. Aquatic Stadium with a capacity of 6,000 visitors (FINA Standard).

4. Aquatic Stadium with a capacity of 6,000 visitors (FINA Standard).

5. Multisports Arena with a capacity of 3,000 visitors.

6. Water Sports Center.

7. Sports Mall (41,000 m2). Children's playground, Splash-N-Surf.

8. Promenade and pedestrian path around the site.

9. Singapore Sports Museum and Youth Olympic Museum

10. Library.

11. Velodrome Arena.

12. $24 / 7$ public facilities (beach volleyball \& multisports court).

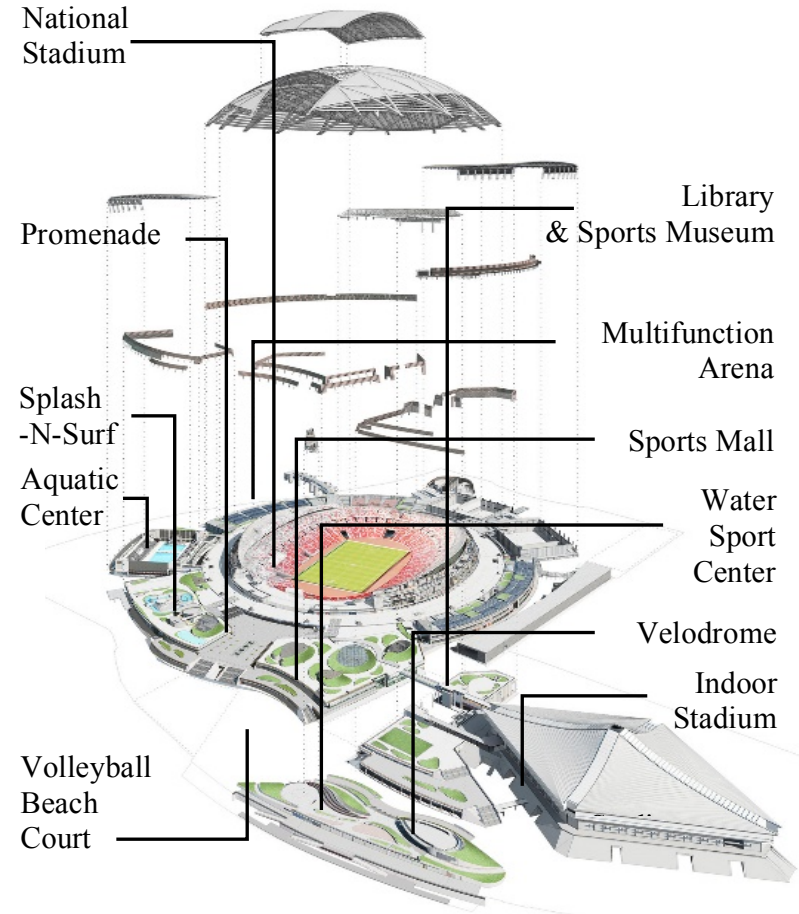

Figure 7. Singapore Sports Hub Scheme with Annotation Source: Sportshub.com.sg

\section{MethodOLOGY}

This study aims to explore the physical form of the Singapore Sports Hub in Kallang, Singapore. The method used is a qualitative method that refers to the principles of High-tech Architecture.

\section{A. Data Collecting Method}

The data, collected through the literature review method that is sourced from printed and electronic literature. The objects are assessed such as; building mass blocks, outer space, inner space, structure, material, and façades.

\section{B. Analysis Method}

The collected data are reviewed using literature data on the principles of High-tech Architecture so that the temporary conclusions can be generated.

\section{Conclusion Method}

Based on the temporary conclusion, the objects of study that applies the principles of High-tech architecture is summarized in the observation table so that the conclusions can be obtained. 


\section{ANALYSIS}

\section{A. Block Plan (building mass)}

Main building mass

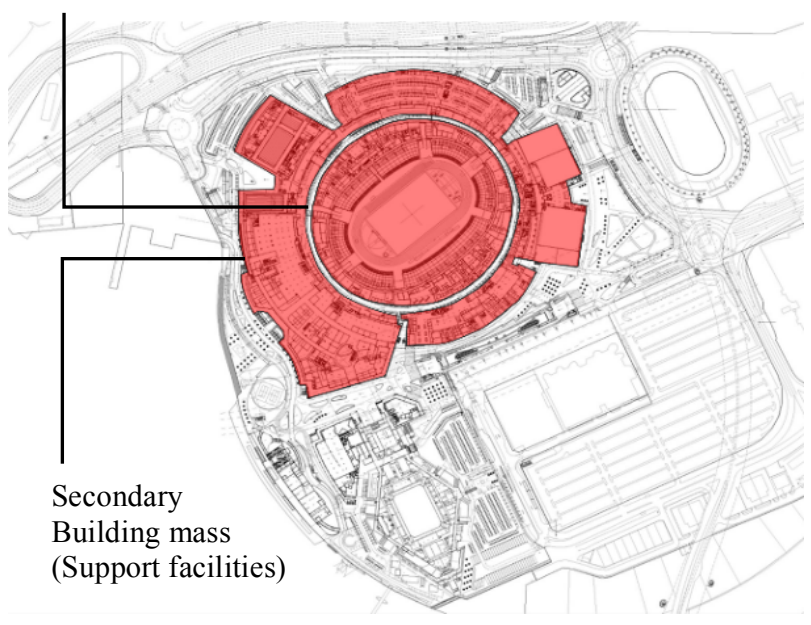

Fig. 8. Singapore Sports Hub block masses Source: Processed from sportshub.com.sg

The Singapore Sports Hub has a centralized space organization. The mass of buildings with a secondary orientation at the center, which is oriented to the mass of the main building (national stadium) as a binding center.

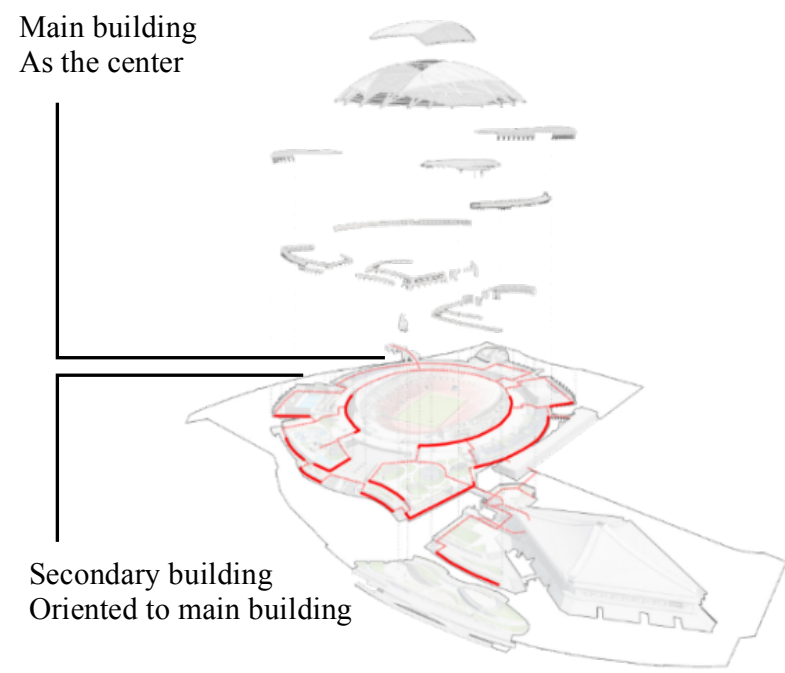

Fig. 9. Singapore Sports Hub's Block Masses Scheme

Source: sportshub.com.sg

Based on the applied space organization, the Singapore Sports Hub's block masses have a circular shape combined with an asymmetrical form to respond to the shape of the site and the function of the main building [3].

The dynamic form of building masses forms a unique and not outdated mass of buildings.

So that the form of building blocks of mass can fulfill the principle of "Optimistic Confidence in Scientific Culture".

\section{B. Site Plan (outdoor)}

Outdoor space with multipurpose function

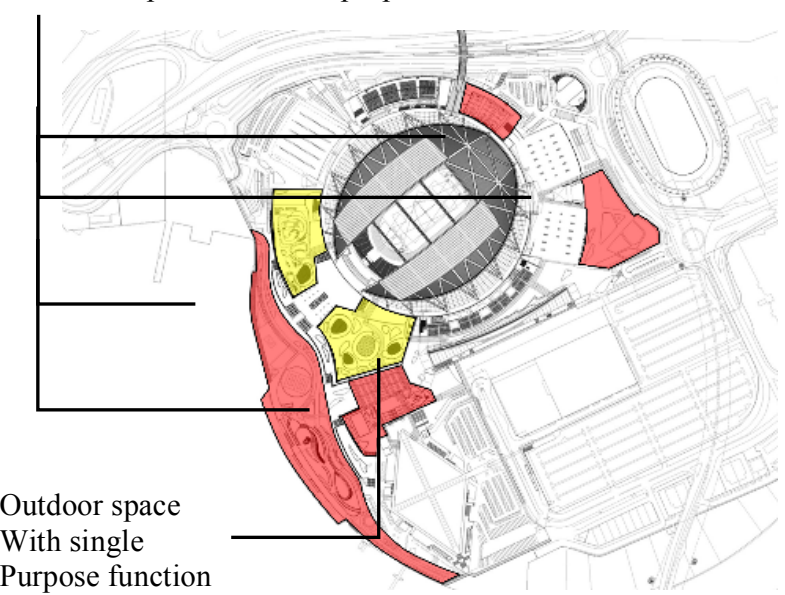

Purpose function

Fig. 10. Outdoor Space with various types of purposes on site Source: Processed from sportshub.com.sg

Based on a dynamic mass block, it indirectly forms a unique outer space. In response to this, outdoor space that has a pessimal size for formal event functioned as a space with high flexibility activities to adapt to changes both perceptually and physically. The outdoor spaces around the site are also connected directly to the indoor space.

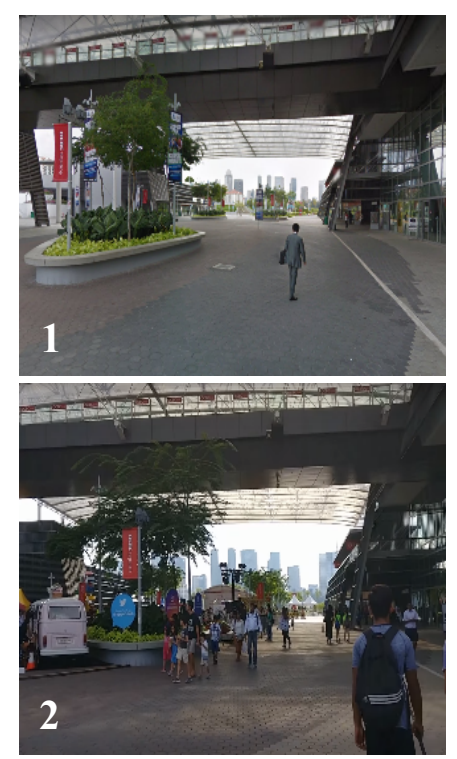

Fig. 11 \& Fig. 12. Application of Outdoor Multipurpose Space of Singapore Sports Hub

1. Outdoor Space that Functioned as Pedestrian Ways around the Site 2. Outdoor Space that Functioned as Center for Local Communities Activities

Source: Processed from Google Maps 2019

The use of outdoor space of the Sports Hub is functioned by the needs of the space requirements so that the flexibility of the outdoor space did not change the physical shape and size of the Singapore Sports Hub's outdoor space. 


\section{Floorplan (indoor space)}

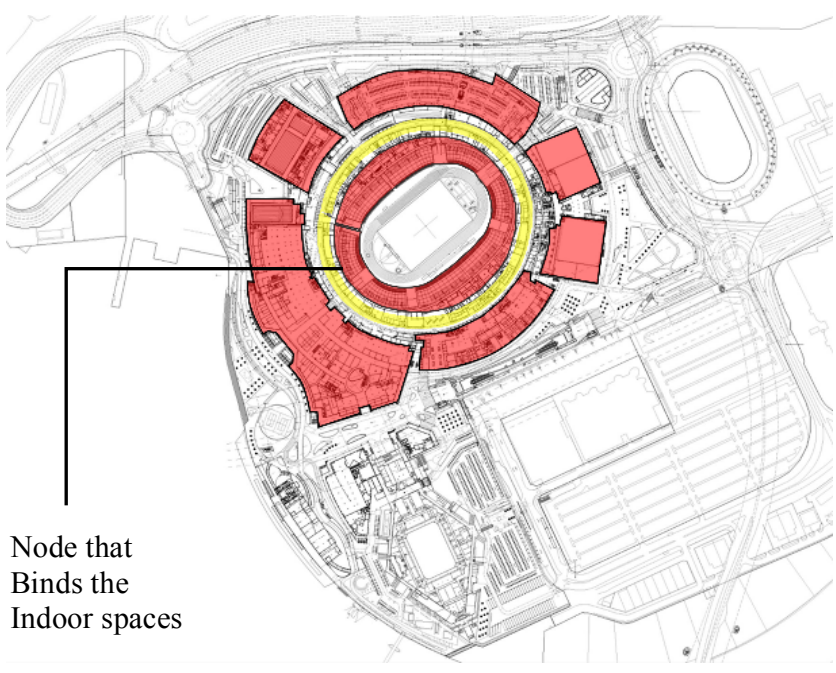

Figure 13. Indoor space functioned as main facilities connected with corridor (node)

Source: Processed from sportshub.com.sg

The design of the indoor space of Singapore Sports Hub also applies the principle of 'Flexible Space' which connects each venue and support facilities with the node (corridor) of the building. The node functions as a circulation channel that is distinguished by the floor.

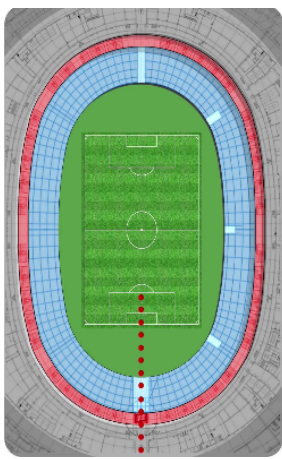

1

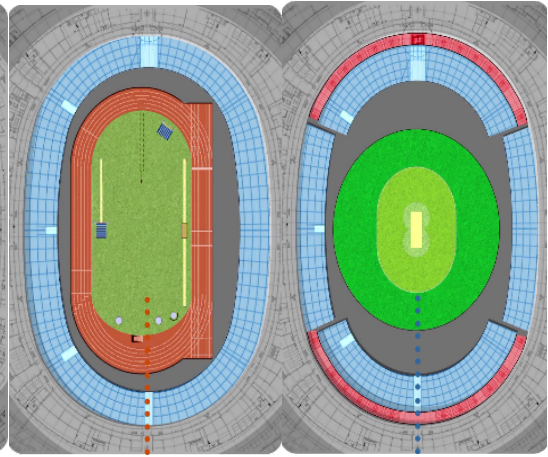

2
3
Fig.14. Multipurpose on Main Building

1. Soccer Mode, 2. Athletic Mode,

3. Cricket Mode

Source: Processed from Dragages Singapore

(Accessed 1st April 2019)

The distinguished of the main facilities, especially the National Stadium has technology that allows the grandstand (audience seats) to be moved so that they can maximize the amount of space to fulfill the size's requirements of a particular event.

\section{Structure}

Emphasis on the structure that prioritizes the principle of 'Lightweight and Tensile Structure and Celebration of Process', divided to:

1. Body, the main body structure of Singapore Sports Hub used a conventional structural system, in the form of concrete construction to effectively hold tribune loads. The Sports Hub body structure also serves as a partial deterrent to the roof construction.

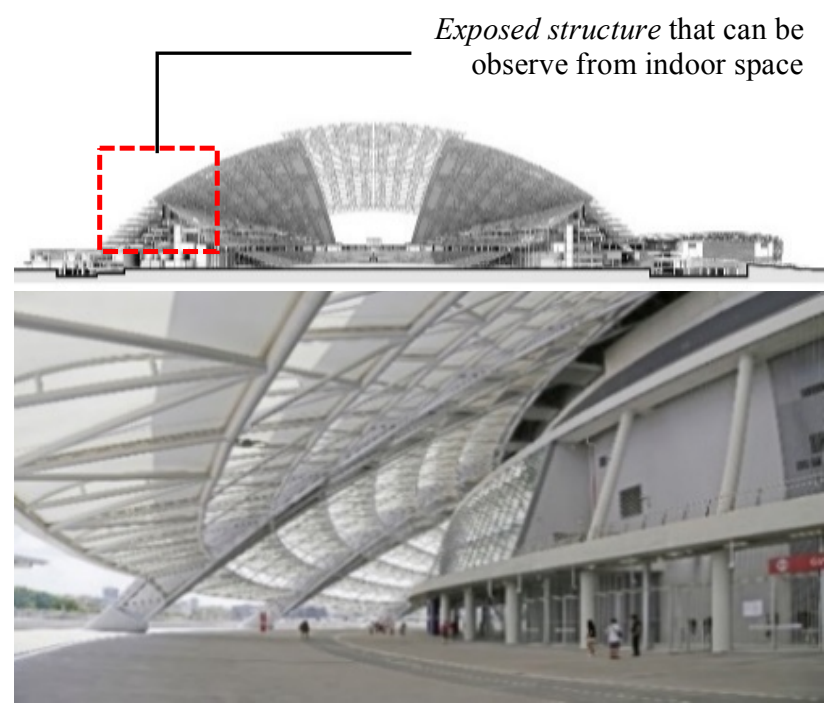

Fig. 15. Construction System of Singapore Sports Hub Body

Source: Processed from sportshub.com.sg

(Accessed 1st April 2019)

So that the application of the exposed structure can be observed on the pedestrian path under the dome.

\section{Head (Roof)}

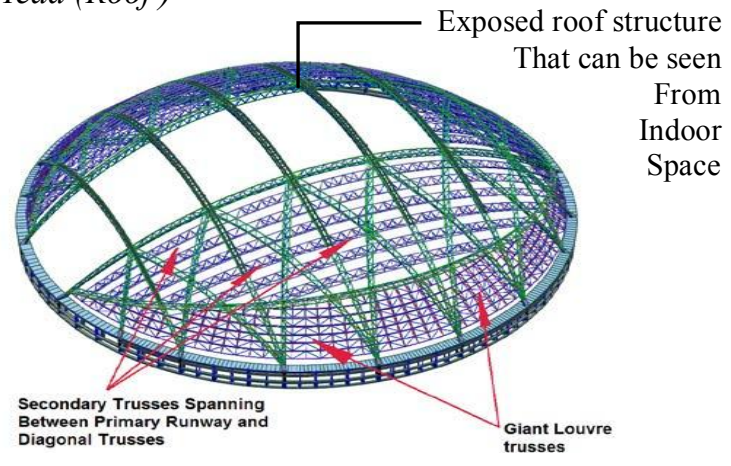

Fig.16. Roof Construction System

Source: tekla.com [7]

(Accessed 8th April 2019)

The roof system using a space truss structure. The structures arranged like a half-ball dome. Thus, a wide enough distance can still be covered with lightweight and strong materials. 


\section{E. Materials}

To meet the functions and needs of space requirements, especially the roof construction requires strong and lightweight material and can represent the material of the future. The use of the latest / latest material refers to the principles of 'Transparent, Coating, and Movement' and 'Optimistic Beliefs in Scientific Culture'.

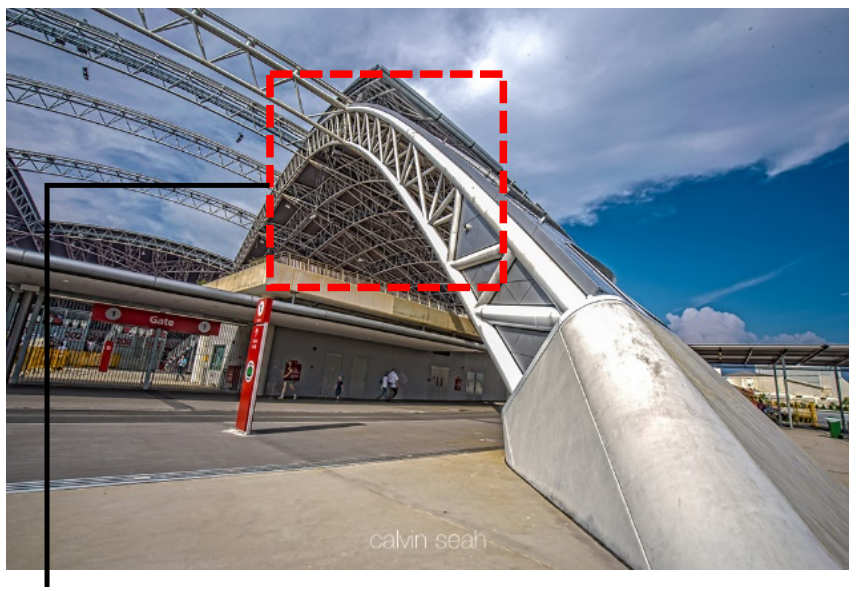

Cover material of the roof system made from steel

Fig. 17. Materials of the Singapore Sports Hub Source: Processed from sportshub.com.sg (Accessed 1st April 2019)

The material used for the roof structure is a steel bar arranged in a half ball dome. The material used forms of High-tech characteristics.

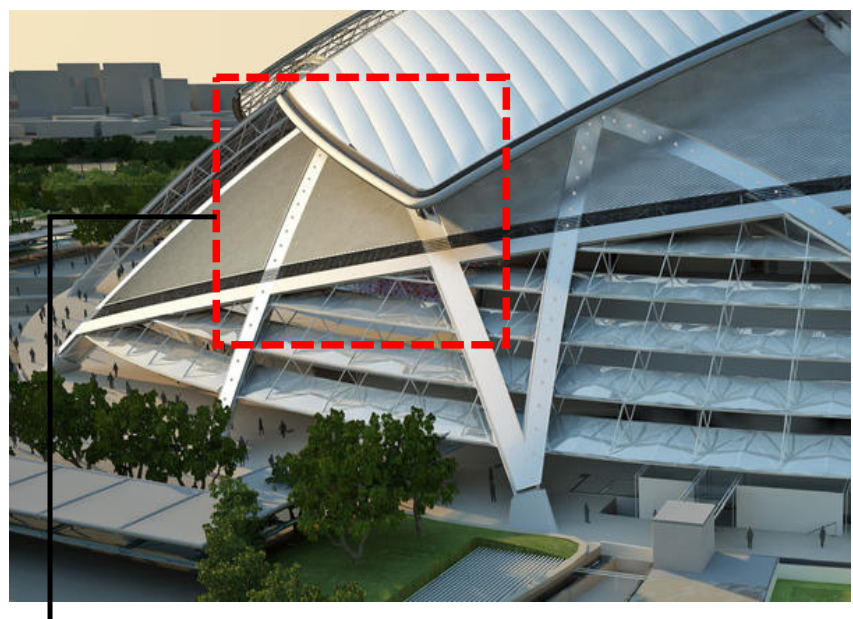

Roof cover's material

From PTFE (Polytetrafluoroethylene)

Fig. 18. Singapore Sports Hub Roof Cover Materials

Source: Processed from sportshub.com.sg

(Accessed 1st April 2019)

The roof cover material of the building is coated with PTFE (Polytetrafluoroethylene) and membrane fabrics that suitable for wide spans roof construction.

\section{F. Façade}

The façade of the Sports Hub refers to the High-tech architecture principles, such as 'Inside Out' and 'Bright and Prevalent Coloring'.

Using transparent materials such as PTFE materials (Polytetrafluoroethylene) and membranes, openings on the Southwest and Southeast sides of the building to expose the interior.

By applying this, the main corridor (unifier), the venue's façade and important spaces in the building can be highlighted. So that the flow of accessibility and activities can be well identified from the outside.
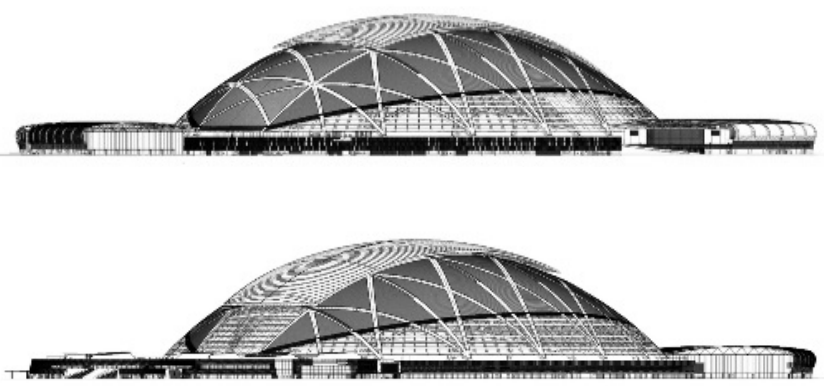

Fig. 19. Southwest and Southeast Elevations of Singapore Sports Hub

Source: Processed from sportshub.com.sg (Accessed 1st April 2019)

The Sports Hub's interior can be seen from the outside, so users can see and understand to reach their destination.

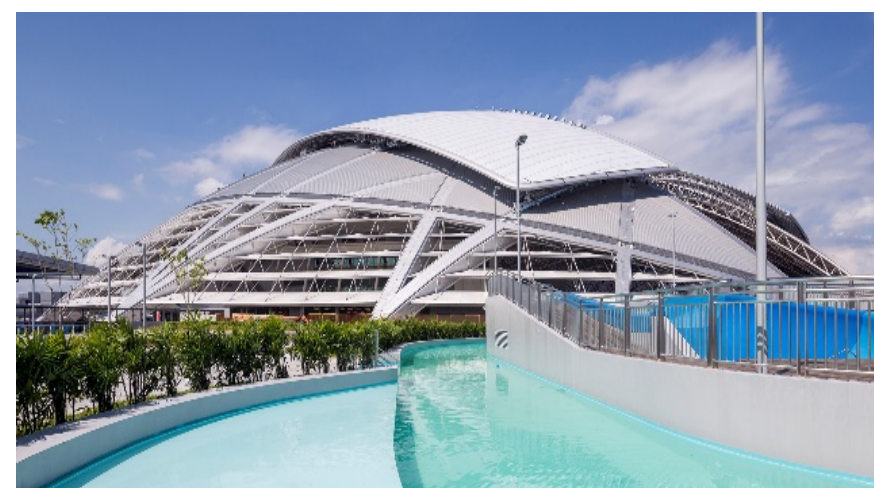

Fig. 20. Singapore Sports Hub's façade

Source: Processed from sportshub.com.sg (Accessed 1st April 2019)

The use of bright colors on the building façade uses primary colors (white) that are applied to the supporting structure and roof cover.

But, this color selections can complicate the observer to determine the parts of the building.

So that the application of the principle of 'Bright and Prevalent Coloring' is less effective in the building. 
G. Observation Result: The Optimal Application of High-tech Architecture

Matrix of the Application of High-Tech Architecture Principles on the Singapore Sports Hub

\begin{tabular}{|l|c|c|c|c|c|c|c|}
\hline $\begin{array}{r}\text { Principles } \\
\text { of High- } \\
\text { Assessed } \\
\text { Objects }\end{array}$ & $\begin{array}{c}\text { Inside } \\
\text { Out }\end{array}$ & $\begin{array}{c}\text { Celebration of } \\
\text { Process }\end{array}$ & $\begin{array}{c}\text { Transparent, } \\
\text { Coating and } \\
\text { Movement }\end{array}$ & $\begin{array}{c}\text { Brightness } \\
\text { and } \\
\text { Prevalent } \\
\text { Color }\end{array}$ & $\begin{array}{c}\text { Lightweight } \\
\text { and Tensile } \\
\text { structure }\end{array}$ & $\begin{array}{c}\text { Optimistic } \\
\text { in scientific } \\
\text { culture }\end{array}$ & Flexible Space \\
\hline Block Plan & & & & & & $\checkmark$ & \\
\hline Site Plan & & & & & & & \\
\hline Floor Plan & & & & & $\checkmark$ & & $\checkmark$ \\
\hline Structure & & $\checkmark$ & & & & $\checkmark$ & \\
\hline Materials & & & $\checkmark$ & & & & \\
\hline Façade & $\checkmark$ & & & & & & \\
\hline
\end{tabular}

Based on the study, the application of the High-tech Architecture principles on Singapore Sports Hub applies six out of the seven principles optimally.

\section{ANALYSIS}

The Singapore Sports Hub is an integrated Olympic-scale sports hub that connected with the support facilities center (entertainment and lifestyle hub) located in Kallang, Singapore which was built in 2014 [1].

The application of the High-tech Architecture principles on Singapore Sports Hub, each object is assessed for its optimization, including block masses, outdoor space, indoor space, structure, materials, and façade.

Based on observations, Singapore Sports Hub has applied six out of the seven principles of High-tech Architecture principles optimally, such as:

\section{Inside Out,}

2. Celebration of Process,

3. Transparent, Coating and Movement,

4. Lightweight and Tensile Structure,

5. Optimistic Belief in Scientific

Culture,

6. Flexible Space.

Based on the data above, the Singapore Sports Hub is a sports hub that applies a good category of High-tech architecture.

\section{REFERENCES}

[1] ArchDaily. Singapore SportsHub / DPArchitects, 2014. Retrieved from ArchDaily website: https://www.archdaily.com/523365/singaporesportshub-dparchitects

[2] C. Jencks. The Battle of High-Tech, Great Building with Great Faults. London: Thames and Hudson, 1988.

[3] F.D.K. Ching, Architecture: Form, Space, and Order (4th ed.). John Wiley \& Sons, 1979.

[4] Dragages Singapore Limited. SINGAPORE SPORTS HUB. Retrieved from http://dragages.com.sg/projects-post/singaporesports-hub/

[5] Singapore Sports Hub. ABOUT US WHERE SINGAPORE COMES TO PLAY. Retrieved from https:/www.sportshub.com.sg/about

[6] Sugiyono. Metode Penelitian Kuantitatif, Kualitatif, dan R\&D. Bandung: CV. Alfabeta, 2006.

[7] Trimble Solutions Corporation. The Singapore Sports Hub. Retrieved from https://www.tekla.com/in/references/singaporesports-hub

[8] Weliam. Maguwoharjo Sport Center di Yogyakarta. Universitas Atma Jaya Yogyakarta, 2015. Retrieved from journal.uajy.ac.id/8642/1/JURNALTA13821.pdf 